\title{
Collaboration is key to success for transition of newly licensed nurses to specialty areas
}

\author{
Jo-Anne Senneff, Carol LaMonica-Way, Krendi Walls, Gilbert Barrera Jr., Harvinder Kaur, Susan Kilbourn, Janice \\ McKay \\ Houston Methodist, Houston, Texas, USA
}

Received: February 25, 2019

Accepted: May 14, 2019

Online Published: August 16, 2019

DOI: $10.5430 /$ jnep.v9n12p13

URL: https://doi.org/10.5430/jnep.v9n12p13

\begin{abstract}
Newly licensed nurses gain knowledge and skills at the academic level to enter the profession as novice nurses. A nurse residency program is crucial in the successful transition of new nurses to their professional role. In addition, supportive structures are essential for new nurses to acquire the skills, knowledge, and decision-making abilities appropriate for their specific area of practice. At Houston Methodist, an additional element of the nurse residency program includes transition to practice classes that are designed to increase new nurses' knowledge and understanding of relevant skills. The classes provide practice in specific environments and improve self-confidence with elements identified through Casey-Fink surveys. In addition to the initial classes developed to support these areas, feedback showed the need to incorporate specific classes for specialized environments. As a result, the coordinators of the nurse residency program, experts, and leaders from specialty areas explored and developed specific learning opportunities. The aim of this article is to showcase the strategies used to develop customized approaches to ensure successful transitions to practice for newly licensed nurses.
\end{abstract}

Key Words: Newly licensed nurses, Nurse residency program, Specialty areas, Transition to practice

\section{INTRODUCTION}

Accredited academic nursing programs provide a standardized approach with key elements required for a newly licensed nurse to enter the nursing profession. Nursing students receive generalized training and education to be able to safely care for patients. Although the nursing students are exposed to various clinical settings, these clinical rotations do not adequately provide all the required skills, knowledge, and exposure required, especially for nurses practicing in specialized clinical areas. Their education provides the theoretical framework to enter nursing practice, but every clinical setting requires additional knowledge and skills to effectively care for patients and their families.

Strategic planning of health care organizations needs to in- corporate a safe environment in which nurses can acquire these additional proficiencies. ${ }^{[1]}$ Providing additional learning opportunities to enhance nurses' knowledge and skills related to a specific practice area can improve self-confidence and decision-making related to that area. To meet this need, the Houston Methodist Nurse Residency Program (NRP) introduced transition to practice (TTP) classes specific for specialty environments to provide additional education for the area of practice.

\subsection{Nurse residency programs}

Newly licensed nurses are now the largest workforce in professional nursing. ${ }^{[2]}$ As a result of challenges encountered during the transition to their professional roles, a signifi-

*Correspondence: Jo-Anne Senneff; Email: JASenneff@ houstonmethodist.org; Address: Houston Methodist, Houston, Texas, USA. 
cant number of newly licensed nurses leave the profession; therefore, it is essential to provide these new nurses an appropriate support structure. Before the inception of formalized NRPs, organizations experienced turnover rates as high as $75 \%$ of newly licensed nurses, costing hospitals $\$ 22,000$ to $\$ 77,000 .^{[2]}$ Turnover results in staffing challenges that add to the frustration and dissatisfaction of the entire health care team. The implementation of NRPs can help to diminish this effect. These programs have proven to be a cost-effective measure for health care organizations to combat the turnover crisis among newly licensed nurses. ${ }^{[3]}$

Health care organizations must provide support and guidance to ensure the successful transition of newly licensed nurses to the clinical practice environment. Strategic implementation of NRPs that focus on building new nursing graduates' confidence and competence can help to ensure their transition from academia to the practice environment. Health care organizations need to understand how changes in the health care landscape impact newly licensed nurses who are transitioning to the practice environment. Caring for patients is becoming more complex because of multifaceted patients, technology, and demands. ${ }^{[4]}$ Having a structure like a NRP to support the newly licensed nurse can support the transition to his or her professional role. In addition, an accredited program is recommended since it ensures standardization and a consistent practice, content, and outcomes. ${ }^{[5]}$ As a result of the generalized training as the standard for entry to practice, additional specialized training is required to meet the needs of specific practice areas. The literature overwhelmingly validates the importance of NRPs and their implementation; however, it is also vital to incorporate additional support and resources within these programs for specialty practice areas.

\subsection{Specialty training}

Newly licensed nurses require specific knowledge and skills for practice in certain specialized areas like intensive care, progressive care, women's services, peri-operative service, and so on, which can best be provided by designing and implementing evidence-based specialty training programs. ${ }^{[6]}$ Several authors share the importance of supporting newly licensed nurses in the transition to their professional roles and providing opportunities to learn the skills and knowledge required for their specific practice environment. Specialized training for the newly licensed nurse, utilizing various strategies, is required to promote confidence, skill acquisition, critical thinking, and positive outcomes. Ensuring that standards of care related to the practice area are introduced guarantees that best practices, guidelines, and protocols are incorporated into practice. ${ }^{[1,7-11]}$

\subsection{Preceptor}

The preceptor is a key player in the successful transition of the newly licensed nurse to the practice environment, providing a primary support structure in the organization. Preceptors help new nurses develop the skills, knowledge, and socialization within the clinical environment that allow them to become fully contributing partners within the health care team. ${ }^{[12-14]}$ The preceptor is instrumental in providing a positive learning environment that fosters a safe place for newly licensed nurses to ask questions and learn; therefore, providing education, support, and resources for preceptors to develop their role is essential. ${ }^{[12]}$

\section{BACKGROUND}

Houston Methodist System comprises a leading academic medical center in the Texas Medical Center and five community hospitals serving the greater Houston area. The University HealthSystem Consortium/American Association of Colleges of Nursing (UHC/AACN) Nurse Residency Program $^{\mathrm{TM}}$, now known as the Vizient/AACN Nurse Residency Program ${ }^{\mathrm{TM}}$, was implemented in 2004 at Houston Methodist Hospital, a nonprofit health care organization that provides comprehensive medical services. In addition to Houston Methodist Hospital, Houston Methodist San Jacinto Hospital adopted the UHC/AACN NRP curriculum in onboarding nurse residents in 2009. The other hospitals in the system supported new nurses with a homegrown approach. To ensure best practices in safe patient care and to standardize practices to promote optimal patient outcomes, Houston Methodist moved toward a system-wide approach, including nursing education and professional development. Aligning nursing education with the strategic approach, the chief nursing officer council approved the implementation of a systemwide NRP. The Houston Methodist NRP program thus transitioned to a system approach, thereby ensuring a stronger alliance between the system hospitals, enhanced educational opportunities, increased access to resources, and support for the nurse resident. In 2015, the Houston Methodist NRP became one of the original system-accredited nurse residency post-baccalaureate programs, meeting the standards of the Commission on Collegiate Nursing Education.

The foundational structure of the Houston Methodist NRP follows the evidence-based Vizient/AACN curriculum. Session topics are focused on core outcomes, including critical thinking skills, patient safety, nurse leadership, and ongoing professional development. The delivery and the framework of the program have been individualized to align with the mission, vision, and values of Houston Methodist. The orientation of a newly licensed nurse incorporates the following elements: General hospital orientation; nursing-specific 
orientation comprising pertinent system-wide and institutional protocols, procedures, technology, and equipment; clinical unit orientation; TTP classes; and the delivery of NRP core content through monthly 4-hour sessions. The Houston Methodist NRP is a hybrid approach consisting of the 8-hour TTP classes followed by the 4-hour monthly sessions over 13 to 15 months.

As a result of feedback from leadership and failures-torescue, the need for additional knowledge, skills, and critical thinking related to the specific practice environment was identified early in the inception of the Houston Methodist NRP. TTP classes were added after hospital orientation and within the first 12 weeks of hire. The TTP classes included interprofessional experts from clinical backgrounds consisting of legal, diabetes nurse educators, respiratory therapists, and nurse practitioners. Following the didactic sessions, a skills day was included related to the topics discussed. These classes were for all newly licensed nurses regardless of practice area.

After moving to a system-wide approach to the residency program, TTP classes remained an important aspect of the program. The first system-wide cohort provided an opportunity for further evaluation and review of the curriculum to ensure the needs of each campus could be met. Early in the process, various practices existed and standardization became paramount. Through feedback from all campuses, residents, and leaders, the need for a different approach to the TTP classes was identified. During the program, the residents who were hired in specialty units began to express concern that their specialty needs were not being met. The residency coordinators focused on these expressed concerns and began to look at the opportunities within the system to examine specialty practice skills development.

The perioperative environment had a strong program that combined the essentials developed from the Association of periOperative Registered Nurses (AORN) and the best practices specific to the organization. Newly licensed nurses hired for the perioperative area participate in this hybrid educational offering to improve knowledge, skills, and decisionmaking related to the area. After examining this program, it was determined that a similar approach was needed to meet the needs of the other specialized practice areas.

Various campuses were using online resources in orientations to specialty areas such as the intensive care unit (ICU) and the emergency department (ED). Application of these resources was determined to be valuable for all campuses. For example, new nurses would be assigned to American Association of Critical Care Nurses' Essentials of Critical Care

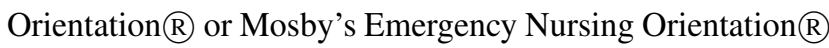

if they worked in an ICU or ED, respectively. Nurses are granted access to these programs for 1 year, so the programs remain a reference for the learner. These software programs are specifically designed for ICU and ED orientation. In addition to the technological aspect, the need for specific classes was identified, and the classes were added to the curriculum for newly licensed nurses hired for the EDs and ICUs at all campuses. The specialty personnel in these areas worked closely together to ensure the needs of the learners were met. The coordinators of the Houston Methodist NRP actively participated in these system-wide councils to provide bidirectional communication incorporating feedback from the residents.

\section{Strategies}

\subsection{Collaboration with experts}

One key step, in the process of standardization, is to have the appropriate stakeholders at the table. Experts in the field are essential for identifying the fundamental elements related to the area of practice. Using educational design principles to guide the process, the Houston Methodist NRP coordinators began to explore options for standardizing the onboarding of newly licensed nurses, specifically including current bedside nurses to help facilitate the specialty TTP classes. Coordinators brought their expertise from specific clinical practice areas and knowledge of campus-related practices to ensure that all needs were met. Historical practices were reviewed and compared with recommendations from specialty organizations. Evaluations from the educational offerings and informal feedback from the nursing leadership, nurse residents, and interprofessional team were also included. Some disparities in training at the specialty level at each campus were identified, and the need to develop a strategic plan for specialty TTP tracks for specific practice areas was recognized.

Using their own practice expertise, the coordinators of the Houston Methodist NRP collaborated with organizational experts in the field to review historical practices at each campus. In addition, established courses from professional organizations such as the Emergency Nurses Association (ENA), American Association of Critical Care Nurses (AACN), AORN, American Society of PeriAnesthesia Nurses (ASPAN), and Association of Women's Health, Obstetric and Neonatal Nurses (AWHONN) were reviewed. Other strategies included collaboration with professional organization members in the community to explore best practices and required practice elements for the specialized environments. Continued analysis of the Casey-Fink survey results, a 39-question instrument developed specifically for graduate nurses to measure nurse resident perception of competency, 
preceptor support, and integration into the clinical unit during the first year of practice, identified opportunities for specific educational offerings and training.

Various strategies were used to develop and enhance the educational options for the specialized areas, including outside resources and expertise. For example, consultants for the ED were accessed to examine practices and provide recommendations for this environment. One of the recommendations was to standardize training for any nurse new to this practice area regardless of experience. A universal course aligned with ENA standards of practice was introduced. Following the initial class, the course curriculum was further developed by Houston Methodist ED educators across all hospitals to enhance new ED nurse preparation. Additionally, as a result of collaboration with the Houston Methodist NRP coordinators, the ED educators realigned the course days and dates to improve nurse resident satisfaction and success. By realigning the program course dates, the nurse residents were provided enhanced learning opportunities and were allowed sufficient time to complete their unit-based orientation, complete the learning module, and attend the required specialized TTP and NRP sessions.

In addition, as a result of the expertise of one of the Houston Methodist NRP coordinators, disparities in women's services across campuses was minimized, and residents hired into this area across the system consistently began to participate in The Houston Area Collaborative Perinatal Program (HACCP). This program includes classes designed to foster the skills, knowledge, and critical thinking required of perinatal nurses. Also, a TTP day was created specifically for the perinatal specialty that included several hands-on activities.

Another area identified through collaboration with the coordinators of the Houston Methodist NRP was the need for standardization of the learning opportunities for the higher acuity environment (ICU and intermediate care unit). Multiple clinical experts collaborated to develop a comprehensive progressive care orientation TTP class to address this need.

Houston Methodist NRP TTP specialty classes now address the needs of specialty clinical practice environments, including perioperative (post-anesthesia care unit and operating room), ED, ICU, intermediate care, and perinatal services (labor and delivery and mother and baby) and medical-surgical practice areas. Additional training is provided at the unit level related to the patient population served, with a focus on the equipment and medication specific to the area, for example, chemotherapy in the oncology unit.
The collaboration solidified relationships between the nurse residency coordinators and experts in the various fields. It is essential to continue to evaluate, obtain feedback, and assess practice environments to ensure the education provided translates to practice at the bedside and to update the content delivered to meet the needs of patients in specialty areas.

Another important factor to consider in the transition of newly licensed nurses is the need to meet their learning styles by incorporating a variety of different teaching strategies. The newest generation of nurses prefer strategies that keep them engaged. It is imperative to collaborate with them to identify their needs so that educational offerings and the learning plan can be tailored to them. It is also essential to consider the multigenerational workforce when addressing the learning needs of this group.

\subsection{Preceptors}

Preceptors are a key element for the onboarding, transitioning, and retention of newly licensed nurses. At the unit and department levels, newly licensed nurses are supported while working side by side with trained, designated preceptors. The newly licensed nurse-preceptor team partners in monitoring patients' conditions and working with other interprofessional clinical experts to develop an individualized plan of care. Newly licensed nurses are given the chance to manage patient care assignments with varying acuity as they progress through their daily milestones. The partnered experience ensures that they can manage resources and workflow, anticipate patient needs, and achieve optimal patient outcomes with the support of the preceptor. During the unit orientation, newly licensed nurses actively participate in interprofessional rounds such as care coordination rounds and progressive care rounds and have the opportunity to interact with the interprofessional team. Furthermore, hourly rounding, use of the white board to communicate the plan of care, bedside shift reporting including positive language, and professional behaviors are all part of the role modeling and coaching at the bedside.

Preceptors are key to the successful transition of the newly licensed nurse to the clinical environment; therefore, it is essential to provide adequate skills and knowledge development for these nurses. Initially, each hospital provided a homegrown educational offering to support preceptors. Feedback from the newly licensed nurses, preceptors, and leadership identified a need to standardize the orientation of preceptors at all Houston Methodist hospitals. The System Interprofessional Education Council challenged its members to develop a task force to review, update, and standardize a system-wide preceptor orientation program. Standardization 
of practices demanded collaboration of experts. A systemwide preceptor course, "Leading with Excellence: A Comprehensive Preceptor Workshop," was established to ensure this standardization.

\subsection{Planning}

Planning is a critical aspect for the successful transition of newly licensed nurses. It is essential to plan with the experts, the leadership of the various units, and the educators leading the educational offerings to ensure scheduling provides the ideal combination of class learning and on-the-unit training. This process begins several months to a year prior to the onboarding of the newly licensed nurses. The ideal approach is to standardize the onboarding time frame to have all newly licensed nurses start their employment within a designated time. This allows nurses within the cohort to begin building relationships from the time of onboarding. In addition, this allows for coordination of the educational offering to be respectful of the experts' and educators' time. It ensures that resources are managed so that classroom space is adequate, personnel are available to support the activity, and unit-based schedules can be established. As newly licensed nurses are hired to other specialized areas, the nurse residency coordinators meet with the leadership and experts from these environments to develop a prescriptive orientation that meets the needs of the learner to ensure success. Examples include the catheterization laboratory, dialysis unit, and infusion center. On the basis of feedback from the newly licensed nurses, the TTP specialty classes occur after time on the unit to obtain unit-based experiences. As a result, the participant can better understand and relate the content to practice. Unit leadership and educators in each specialized environment receive the outlined 13-month calendar of all required sessions including the TTP specialty classes to ensure attendance.

\section{Conclusion}

The transition of newly licensed nurses to their professional roles and clinical specialty environments can be challenging. However, with the appropriate resources and support, these challenges can be minimized. Coordination and collaboration, both as a team and as a system, are extremely valuable. This allows sharing of ideas, expertise, and resources. The early planning and development of the Houston Methodist NRP calendar was imperative to the success of the integration and growth of newly licensed nurses in their professional role. Utilizing standards of practice and providing appropriate strategies for skills, critical thinking, and knowledge acquisition provide the best approach and best practices to ensure high-quality, safe patient care and the success of newly licensed nurses in their specialty environments.

Through formal (surveys) and informal (verbal) feedback, the newly licensed nurses have expressed improved selfconfidence related to their work environment as a result of these specialty TTP classes. The unit leadership have also verbalized an improvement, related to the newly licensed nurses' clinical practice and decision making at the bedside. Additional formalized data collection is required to demonstrate the benefits of the information and skills received for improved practice.

In Conclusion, continuous feedback and evaluation of the orientation plan and educational offerings is essential to ensure the strategies remain relevant and effective for the newly licensed nurse. Additional collaboration among nursing professional development practitioners is required to share effective strategies that support the newly licensed nurse.

\section{CONFlicts OF INTEREST Disclosure}

The authors declare that there is no conflict of interest.

\section{REFERENCES}

[1] Boyer SA, Valdez-Delgado KK, Huss JL, et al. Impact of a nurse residency program on transition to specialty practice. J Nurses Prof Dev. 2017; 33(5): 220-227. PMid:28891876 https : //doi .org/10 $.1097 /$ NND .0000000000000384

[2] Welding NM. Creating a nursing residency: decrease turnover and increase clinical competence. Medsurg Nurs. 2011; 20(1): 37-40.

[3] Africa LM. Transition to practice programs: effective solutions to achieving strategic staffing in today's healthcare systems. Nurs Econ. 2017; 35(4): 178-183.

[4] Hofler L, Thomas K. Transition of new graduate nurses to the workforce challenges and solutions in the changing health care environment. N C Med J. 2016; 77(2): 133-136. PMid:26961840 https://doi.org/10.18043/ncm.77.2.133

[5] Goode CJ, Ponte PR, Havens DS. Residency for transition into practice: an essential requirement for new graduates from basic RN programs. J Nurs Adm. 2016; 46(2): 82-86. PMid:26771476 https ://doi.org/10.1097/NNA.0000000000000300

[6] Innes T, Calleja P. Transition support for new graduate and novice nurses in critical care settings: an integrative review of the literature. Nurse Educ Pract. 2018; 30: 62-72. PMid:29571106 https : //doi.org/10.1016/j.nepr.2018.03.001

[7] Mollohan JK, Morales M. Strategies for successful perioperative orientation. AORN J. 2016; 104(2): 100-110. PMid:27472970 https ://doi.org/10.1016/j.aorn.2016.06.002

[8] Van Camp J, Chappy S. The effectiveness of nurse residency programs on retention: a systematic review. AORN J. 2017; 106(2): 128144. PMid:28755665 https://doi.org/10.1016/j.aorn. 201 7.06 .003

[9] Johnson A, Salisbury H, Johannsson M, et al. Emergency nurse resi- 
dency program evaluation. J Nurses Prof Dev. 2013; 29(5): 233-237. PMid:24060658 https://doi.org/10.1097/01.NND.0000433 908.82754 .10

[10] Valdez AM. Transitioning from novice to competent: what can we learn from the literature about graduate nurses in the emergency setting? J Emerg Nurs. 2008; 34(5): 435-440. PMid:18804717 https://doi.org/10.1016/j.jen.2007.07.008

[11] Morphet J, Kent B, Plummer V, et al. Transition to specialty practice program characteristics and professional development outcomes. Nurse Educ Today. 2016; 44: 109-115. PMid:27429338 https: //doi.org/10.1016/j.nedt.2016.05.017
[12] Clipper B, Cherry B. From transition shock to competent practice: developing preceptors to support new nurse transition. J Contin Educ Nurs. 2015; 46(10): 448-454. PMid:26430864 https: //doi.org/10.3928/00220124-20150918-02

[13] Blegen M, Spector N, Ulrich B, et al. Preceptor support in hospital transition to practice programs. J Nurs Adm. 2015; 45(12): 642-649. PMid:26565643 https://doi.org/10.1097/NNA. 0000000000 000278

[14] Moore P, Spence Cagle C. The lived experience of new nurses: importance of the clinical preceptor. J Contin Educ Nurs. 2012; 43(12): 555565. PMid:22966771 https://doi.org/10.3928/00220124-2 0120904-29 